\title{
New tools to support the designing of efficient and reliable ground source heat exchangers: the Cheap-GSHPs databases and maps
}

\author{
Antonio Galgaro ${ }^{1,2}$, Giorgia Dalla Santa ${ }^{1}$, Michele De Carli ${ }^{3}$, Giuseppe Emmi ${ }^{3}$, Angelo Zarrella ${ }^{3}$, Johannes Mueller ${ }^{4}$, \\ David Bertermann ${ }^{4}$, Amaia Castelruiz ${ }^{5}$, Sarah Noye ${ }^{5}$, Rodolfo Perego ${ }^{6}$, Sebastian Pera ${ }^{6}$, Fabio Poletto ${ }^{7}$, \\ Riccardo Pasquali ${ }^{8}$, and Adriana Bernardi ${ }^{9}$ \\ ${ }^{1}$ Department of Geosciences, Università degli Studi di Padova, 35131 Padova, Italy \\ ${ }^{2}$ National Research Council, Institute of Geosciences and Earth Resources, 35131 Padova, Italy \\ ${ }^{3}$ Department of Industrial Engineering, Università degli Studi di Padova, 35131 Padova, Italy \\ ${ }^{4}$ GeoCentre of Northern Bavaria, Friedrich-Alexander-University, Erlangen, 91054 Nuremberg, Germany \\ ${ }^{5}$ TECNALIA, San Sebastián, Spain \\ ${ }^{6}$ Institute of Earth Science - SUPSI, Campus Trevano, Canobbio, Switzerland \\ ${ }^{7}$ HIREF spa, Tribano, Italy \\ ${ }^{8}$ SLR Environmental Consulting Ireland Ltd. 7, Dundrum Business Park, Windy Arbour, D14, Ireland \\ ${ }^{9}$ National Research Council, Institute of Atmospheric Sciences and Climate, 35127 Padova, Italy
}

Correspondence: Giorgia Dalla Santa (giorgia.dallasanta@unipd.it)

Received: 31 May 2019 - Revised: 30 July 2019 - Accepted: 7 August 2019 - Published: 28 August 2019

\begin{abstract}
The final aim of the EU funded Cheap-GSHPs project is to reduce the total installation cost of closed-loop shallow geothermal systems. As part of the project a Decision Support System (DSS) has been developed and released on the web, in order to support the design of new closedloop geo-exchange systems. The Cheap-GSHP project addresses all the aspects involved in planning and dimensioning a new borefield and therefore, the DSS is composed of several databases and tools that collect and elaborate the preliminary data and information that are necessary during the sizing phase, such as the geological and drilling aspects as well as the heating and cooling building demand.

This paper briefly introduces the content of the databases and the mapping methodology developed for the CheapGSHPs DSS. All these researches are further deepen in the EU project GEO4CIVHIC, with a special attention to the application of shallow geothermal systems for building conditioning to historical buildings.
\end{abstract}

\section{Introduction}

The overall goal of the EU funded Cheap-GSHPs (CHeap and Efficient APplication of reliable Ground Source Heat exchangers and Pumps) project is the development of more efficient and safer shallow geothermal systems for building conditioning, through the reduction of their engineering and installation costs.

In a closed loop geo-exchange system for building conditioning, the transfer of heat between the ground and the building takes place by means of a series of ground heat exchangers inserted into the ground. They are tubes where a heat carrier fluid flows. During winter, this allows the extraction of heat from the ground that is then provided to the building and vice-versa, during summer, the heat is extracted from the building and released into the ground. The whole system is managed by a heat pump, that is an electrical device that transfers the heat between the underground circuit and the heating and cooling circuit inside the building.

When designing a new closed loop Ground Source Heat Pump (GSHP) system, the three most relevant aspects that have to be taken into account are: (1) the location of the building and climate conditions, (2) the building characteristics, such as the use, size, materials and insulation level, and (3) the local ground conditions. The combination of the 
first two elements determines the heating and cooling requirements of the building, whereas the local ground conditions, mainly comprising the stratigraphic sequence and the hydrogeological conditions, determine the local ground heat exchange capacity.

In order to reduce the engineering costs of geothermal heat exchanger sizing, a Decision Support System (DSS) has been developed within the Cheap-GSHPs project to help the users in developing the preliminary design of new geo-exchange systems. The DSS is composed of several analytical linked to system parameter databases to characterize the most important aspects of the new GSHP closed-loop systems design. The DSS tools consider all the aspects of the design of a new borefield, from the geological and drilling issues to the technical and economical ones, by starting from several possible design and operational solutions. Finally, these tools support the user in the selection of the most suitable heat exchanger, the sizing of the borehole field as well as in the choice of the best installation and drilling technique. The Decision Support System and the tools and databases that are part of it, are publicly available on the web (visit the website: http://cheap-gshp.eu/, last access: 26 August 2019).

Given that a big obstacle for the uptake of GSHPs is the lack of public awareness and stakeholders knowledge of this technology, the inexperience of designers in sizing the borefields, the DSS has been targeted at users with different levels of knowledge, so that it can be used by both expert and nonexpert users. Technical stakeholders are designers, architects and researchers. Non-technical stakeholders are public administrations, general investors, end users.

The following databases have developed to support the DSS tools:

i. a detailed Thermo-Geological Database indicating the thermo-physical parameters of a wide spectrum of European lithologies and unconsolidated sediment classes in order to allow the correct evaluation of the heat exchange capacity of the subsoil where a new borehole field has to be installed (Galgaro et al., 2019).

ii. a European geological Map, that represents a first overview of the local superficial geological conditions all around Europe; this is used in both in association with the Thermo-Geological database and also in order to suggest the best drilling technique for the local geological setting (Mueller et al., 2018);

iii. a pan-European Climatic Database, that is based on different test reference years as well as on the classification based on the Köppen-Geiger scale (described in De Carli et al., 2018);

iv. a standard temporal profiles database of the heating and cooling requirements for several standardized typologies of buildings, by taking into account three different levels of thermal insulation in building (Badens et al., 2016). v. a heat pumps database, to support the user in the choice of the best heat pump, based on a sort of catalogue of all the mechanical/electrical components of the heat pumps. It allows the definition of the Coefficient of Performance (COP) and the Energetic Efficiency Ratio according to EN 14511 and helps in the identification of the heat pump operating curves, according to the EnergyPlus software.

Finally, a method to represent on local thematic maps the techno-economic potential of a territory with regards of closed-loop shallow geothermal systems has been developed. This mapping method merges all geological, climatic and energetic data collected in the previous databases, in order to quantify the geothermal potential for different locations and the feasibility of several kinds of ground heat exchangers. This method has been successfully applied in some test sites representative of main European contexts (Perego et al., 2019b).

The DSS will help the designers in correctly sizing new GSHP systems and to avoid undersized borefields. These have to be avoided in heating dominated building demands in depositional low plain geological settings, as the thermal alteration induced in the underground can lead to freeze-thaw cycles, mechanical and thermal properties alteration can occur in cohesive deposits (Dalla Santa et al., 2016a, b, 2019a, b).

All these researches are further deepen in the EU project GEO4CIVHIC, with a special attention to the application of shallow geothermal systems for building conditioning to historical buildings.

\section{The DSS databases}

\subsection{Detailed thermo-geological database}

When sizing a new GSHP system, the Thermal Response Test (TRT) is usually performed to determine the local ground thermal conductivity and other parameters that are necessary for a correct design. The TRT involves a quite large volume of ground and finally provides an equivalent value of the local thermal conductivity by including the whole sitespecific conditions such as the complete stratigraphy, the effects of the groundwater flow, and also the thermal behavior of the borehole heat exchanger itself (probes and sealing grout). When TRT data is not available or too expensive to obtain, a first sizing estimate can be obtained by an "equivalent" value of thermal conductivity that is representative of the entire stratigraphic sequence by associating the thermal conductivity value to each geological layer as indicated by literature. A thermal conductivity value can be associated to each lithology identified in the local stratigraphy, and then an equivalent value of thermal conductivity can be calculated as an averaged value, weighted on the thickness of the deposit itself. The same procedure can be applied to evalu- 
ate the equivalent thermal diffusivity. This procedure is indicated also in the most used worldwide guidelines such as the ASHRAE and the VDI (VDI, 2010), where the thermal properties values are provided (ASHRAE, 2011).

Within the Cheap-GSHPs project, a new thermogeological database has been proposed by merging literature data and direct measurements performed by the project, indicating the variability range and providing a recommended value for the thermal properties of more than 40 lithologies. The database consolidates a wide amount of data present in the international guidelines (VDI and ASHRAE included) and scientific literature (it is based on the values reported in more than 60 references). In addition, the dataset has been integrated with more than 400 experimental measurements performed on samples of rocks and unconsolidated sediments collected in several European countries. The database merges the literature data with the measured ones and indicates a thermal conductivity range and a recommended value for 35 classes of rocks and 10 classes of unconsolidated sediments identified by means of their granulometric composition and water content (see Table 1). Moreover, a new technique was developed to measure the thermal properties of gravels, in order to overcome the issues related to the clasts size and their variability of the mineralogical and lithological composition. A guarded hot plate Taurus Instruments TLP 800 with a measuring plate of $0.8 \times 0.8 \mathrm{~m}$, usually applied to measure the thermal insulation of building materials, was modified for this purpose as presented in Dalla Santa et al. (2017).

The Thermo-Geological Database is directly used in the DSS developed by the Cheap-GSHPs project, to estimate the equivalent thermal conductivity of the ground. In case the local stratigraphy is not available, the user is supported by the European Geological Map described in Sect. 2.2; conversely, as the local stratigraphy is available, the user can indicate the geological layers and the system provides the recommended thermal parameter values of each lithology. In this way, an averaged value for the entire length of the GSHE is automatically calculated by taking into account the thickness of each deposit.

The new proposed Thermo-Geological database augments the number of the lithological classes for which the thermal properties are listed and, in some cases, provides more appropriate values for specific lithotypes, e.g. for trachyte and andesite. The database feeds the DSS but can also be used directly as a standalone dataset. In this case, the user could assign an estimated value of thermal conductivity to the rocks/sediment recognized in the local geological setting by starting from the suggested values ( $\mathrm{min}$, recommended, max values) and by considering the features that most affect the rock thermal behavior, such as porosity/density/state of consolidation, water content, texture and mineralogical composition. The database is described comprehensively in Galgaro et al. (2019).

\subsection{European shallow geological map}

When the local stratigraphy is not available, the user can indicate the new GSHP system location, and the DSS can provide some information about the local underground and its thermal behaviour, by associating the thermal values provided by the Thermo-Geological database. For this purpose, a panEuropean geological map has been developed in order to help designers or end-users by providing a lithological overview of geothermal potentials. The map is based on the on the dominant parent material attribute of the European soil geographical database developed by the Joint Reasearch Center (JCR). The pan-European geological overview map was created using freely accessible JRC data and ArcGIS software and respects the INSPIRE (INfrastructure for Spatial InfoRmation in Europe) guidelines. The map is based on a classification based on hardness, thus allowing assertions about the level of hardness and drillability. This classification was selected as the most practicable data set for incorporating relevant underground data with respect to geothermal properties and it contains geological and pedological information.

Figure 1 shows the geographical distribution of these geological materials among the European countries and through the elaboration of the data grouped into 8 classes.

In addition to the geological setting and the related association with the thermal properties database, the map provides information about the underground drillability conditions all around Europe (in a raster with $1 \mathrm{~km} \times 1 \mathrm{~km}$ spatial resolution) and thereby helps the user in the selection of the most suitable drilling technique (Bertermann et al., 2015).

The availability of this kind of information allows the reduction of the engineering costs during the designing and planning phase. The European Superficial Geological Map is properly described in Mueller et al. (2018).

\subsection{Pan-european climatic database}

When sizing a new shallow geothermal system, the local climate is necessary to correctly identify the proper boundary conditions in terms of energy requirements and comfort in buildings. In addition, climate data are often used to evaluate the ground temperature when it is not available, because no TRT is available or executable.

The climatic tool inserted in the DSS is supported by a database of climatic data where the standard Köppen-Geiger climate classification has been matched with the weather data provided by the EnergyPlus and METEONORM software database. More than 300 locations all around Europe have been considered with their Test Reference Years and finally labelled according to the degree-days for heating and cooling, as well as defined by the Köppen-Geiger scale. In addition, an algorithm based on the lapse rate method (also named smart interpolation) (Stahl et al., 2006; Li and Heap, 2014) is used in the tool in order to obtain temperature data in unknown locations from nearby weather stations, de- 
Table 1. Reference list of material in the Thermo-Geological database (Galgaro et al., 2019).

\begin{tabular}{|c|c|c|c|c|}
\hline $\begin{array}{l}\text { Consolidated-clastic- } \\
\text { sedimentary rocks }\end{array}$ & $\begin{array}{l}\text { Igneous } \\
\text { rocks }\end{array}$ & $\begin{array}{l}\text { Metamorphic } \\
\text { rocks }\end{array}$ & $\begin{array}{l}\text { Unconsolidated } \\
\text { materials }\end{array}$ & $\begin{array}{l}\text { Organic } \\
\text { materials }\end{array}$ \\
\hline Conglomerate & Granite & Quartzite schist & Gravel/dry & Peat \\
\hline Sandstone & Diorite & Micaschist & Gravel and sand/wet & \\
\hline Quartzitic sandstone & Syenite & Gneiss & Sand/dry & \\
\hline Claystone/mudstone & Gabbro & Phyllite & Sand/wet & \\
\hline Limestone & Rhyolite & Amphibolite & Silty sand (sandy silt)/wet & \\
\hline Dolomite & Dacite & Serpentinite & Silt/dry & \\
\hline Marlstone & Andesite & Marble & Silt-clayey silt/wet & \\
\hline Gypsum & Trachyte & & Clay/dry & \\
\hline \multirow[t]{2}{*}{ Anhydrite } & Basalt & & Plastic clay/wet & \\
\hline & Tuff/tuffstone & & & \\
\hline
\end{tabular}

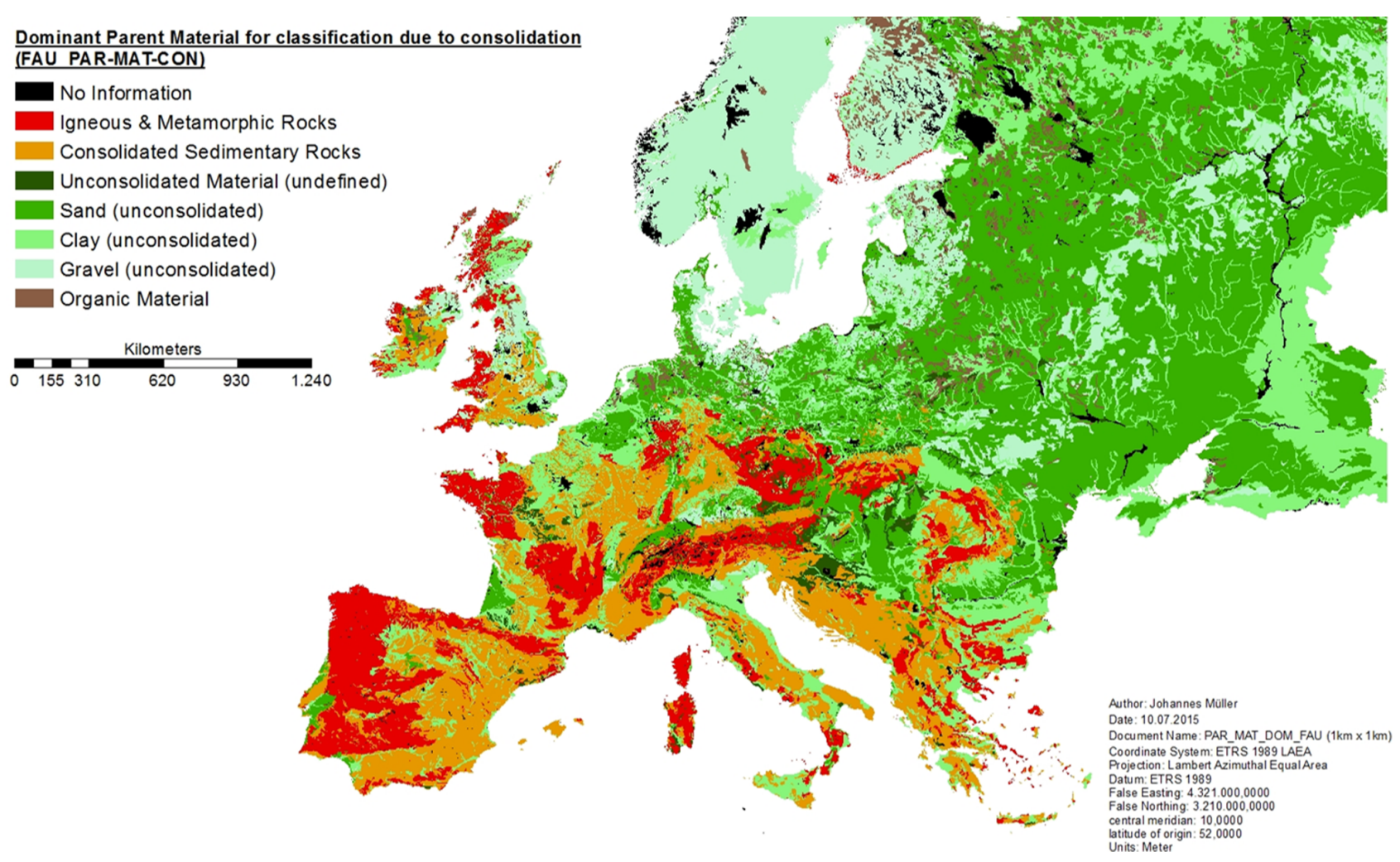

Figure 1. The FAU PAR-MAT-COM European geological map (from Mueller et al., 2018).

spite these being located at different altitudes. The lapse rate method uses the temperature values of the nearest weather station and the difference in elevation to estimate the temperature at the un-sampled site. The estimation is based on the nearest known temperature, the elevation difference between the two points and a specified temperature gradient calculated every month by identifying pairs of low-elevation, highelevation stations close to the interested point and computing vertical temperature gradients. The method and the proposed database are properly described in De Carli et al. (2018).
The tool allows the user in selecting the weather conditions closest to the location of interest. The database can be enlarged by the user by adding other EPW files or other Meteonorm TM2 files. It is also possible to import CSV files defined by the user.

\subsection{Standard temporal profiles database: heating and cooling requirements for referential buildings}

In order to help the user to define the building energy demand, the DSS contains a tool that uses standard temporal profiles for heating and cooling requirements for standard- 
ized types of buildings. The standardization is based on the analysis of the energy behaviour of four residential buildings and five non-residential buildings (single family houses, block of flats, administrative buildings and small commercial buildings, like a day care, three administrative buildings and a municipal building).

On the basis of statistical data and journals concerning the state of buildings around Europe (Badenes et al., 2016) four building categories have been selected as being representative samples of the European residential building stock. The residential building case studies have been classified on the basis of the building category (single house, terraced house and apartment building), also considering the $\mathrm{S} / \mathrm{V}$ ratio, the net area $\left(\mathrm{m}^{2}\right)$, the \% glazed area, the number of storeys, the number of dwellings and the urban structure (stand alone or contiguous). A similar classification has been performed for five categories of non-residential buildings.

Heating and cooling energy profiles obtained from dozens of dynamic simulations have been analysed on a monthly and on an annual basis, in relation to: (i) the building category and use, (ii) the S / V (surface / volume) ratio and (iii) the level of envelope insulation, thus achieving a correlation between the yearly energy demand per served unit area and the yearly degree days. In addition, the correlations obtained for locations of the same climate classification have been further analysed, thus achieving one correlation for each KöppenGeiger climate class.

This standardization process of the heating and cooling demands for standardized categories of buildings is described in detail in Carnieletto et al. (2019). In case the DSS user does not know the real building energy needs, this standardized thermal loads profiles database allows the DSS user to estimate the building energy demand just by inserting very simple information (i.e. the location, building use, floor area of the building and the type of envelope) (see Fig. 2).

\subsection{Heat pumps database}

The heat pump database presents an inventory of the technologies of the different main heat pump components (evaporator, condenser, compressor, lamination mechanism, refrigerants, and controls) in order to provide a selection guide and cost/benefit analysis. This way the DSS user is supported in the selection of the best technological solution for each GSHP system working condition, i.e. working temperatures of the fluids in the ground heat exchanger and in the building circuit plus heating/cooling power. The database provides an overview of the possible composition of a heat pump based on the state-of-the-art and the current best practices and, in addition, proposes the innovative technical solutions $\left(\mathrm{a} \mathrm{CO}_{2}\right.$ heat pump, that is able to release water at high temperature) that have been developed within the Cheap-GSHPs project. This kind of database helps the user in the selection of the proper heat pump, in order to improve the energetic performance of the whole GSHP system and to reduce $\mathrm{CO}_{2}$ emis- sions, by using technical advanced solutions such as internal heat recovery, cascade cycle, electronic expansion valves and innovative refrigerant compressors.

The optimal selection of the heat pump is proposed as a function of heating/cooling power, and the heat carrier fluid working temperatures both in the ground and in the building circuit for both heating and cooling mode. For the best selection, the tool provides the trend of the system energetic performances in several working conditions.

\section{Techno-economic potential mapping method for closed-loop geo-exchange systems}

The definition and quantification of the feasibility and potential for different locations is fundamental to promote the deployment of shallow geothermal closed-loop systems. In addition, the mapping of this information is intuitive and easy to understand even for non-specialists. Small scale maps of the potential (e.g. scale $\geq 1: 100000$ ) can be really useful for designers and architects as well as public administrations and end-users since they could improve the political territorial planning over large areas by helping identifying the most suitable or unsuitable zones for the installation of new GSHP systems. The mapping allows having at a glance all the local territory information, thus promoting the deployment of the GSHP technologies by taking into account the local constraints (e.g. environmental protection areas, geological conditions, built-up areas, roads) at the same time.

With this purpose, the information collected and organized to create the previously described databases, have been further homogenized and elaborated in order to assess and map the energetic potential across Europe. Starting from the previously presented databases, a large amount of numerical simulations were performed in order to correlate ground surface temperature, ground thermal conductivity and the required BHE length forgiven energy demands, already calculated for the standardized building typologies (17 reference building types) depending on the location and local climate. Thanks to these regressions, the required BHE-length for each reference building type becomes a "mappable" parameter. Hence, the maps of the required BHE-length have been produced for several typologies of ground heat exchangers in some test sites throughout Europe. The spatial information has been further elaborated in order to calculate the specific capital cost on the basis of the borehole total length and of economic information about the drillability costs, the installation/labour costs and the heat pump cost retrieved by the consortium partners in their own countries. The shallow geothermal potential could therefore be expressed in terms of the ratio between total costs and prevalent peak load (EUR $\mathrm{kW}^{-1}$ ), which can be defined as a specific capital cost: it considers main costs (drilling, materials, grouting, labour and heat pump cost) and system power of the prevalent peak demand. Finally, the thematic maps representing 


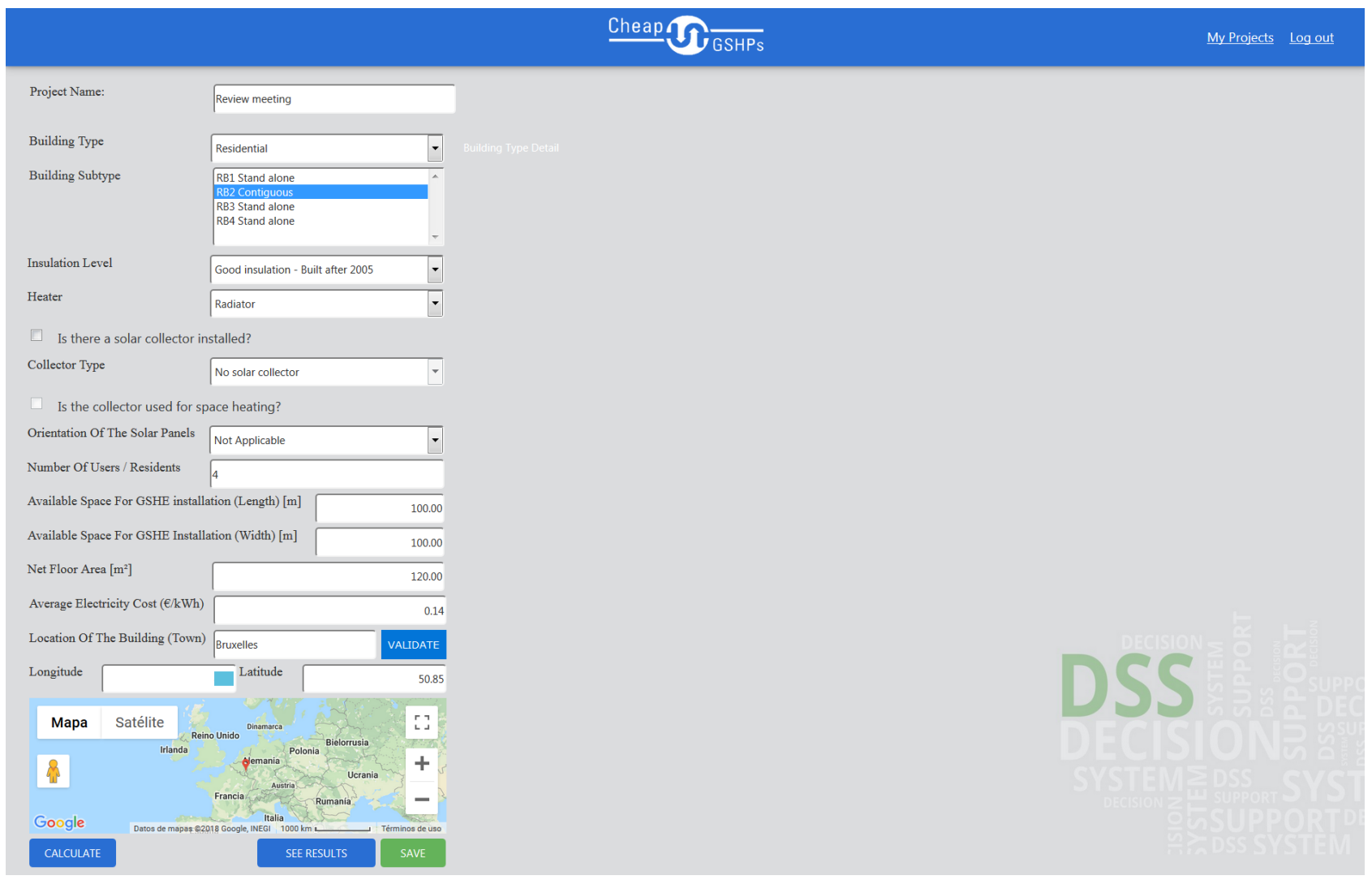

Figure 2. The DSS Website - Facility description page (from De Carli et al., 2018).

the EUR kW ${ }^{-1}$ index has been proposed for seven case studies across Europe (Erlangen in Germany, Dublin in Ireland, Valencia in Spain, Chiasso in Switzerland, Putte in Belgium, Pikermi in Greece and Zagreb in Croatia), in order to test their reliability for different geological contexts, climates and data availability. An example is reported in Fig. 3. The mapping method also allows the comparison of the economic feasibility of different ground heat exchangers on spatial basis. In particular, with regards to the new technologies developed within the Cheap-GSHPs project, maps of economic comparison between actual-state double-U heat exchangers and newly developed enlarged coaxial HE were developed, along with qualitative feasibility maps of helicoidal HE.

The mapping methodology here introduced is properly described in Perego et al. (2019a, b).

\section{Regulatory and licensing procedures}

In addition to these technical aspects, the project examined also the regulatory and licensing procedures (with particular emphasis on risk assessments and environmental impact) and the standards for ground source heat exchanger (GSHE) design and completion for case study sites across Europe (Spain, Greece, Belgium, Ireland, Germany, Croatia, Italy, Switzerland, Romania, Bosnia and Herzegovina and
Serbia). The analysis considers the already existing ground heat exchangers and the new heat exchangers developed as part of the project (described in details in Bertermann et al., 2020 and Pockelé et al., 2020), in order to assess the potential for deployment of the new ones. The implementation of regulations is generally focussed on specific technical aspects relating to the drilling, installation of the ground heat exchanger and long-term operation in the context of heat extraction and heat rejection. The inclusion of ground source heat pumps in buildings such as in the context of local building regulations as part of new build and retrofit works was also considered. The results are presented as brochures for each country which are available in the web site of the Cheap-GSHPs project (http://www.cheap-gshp.eu, last access: 26 August 2019). 


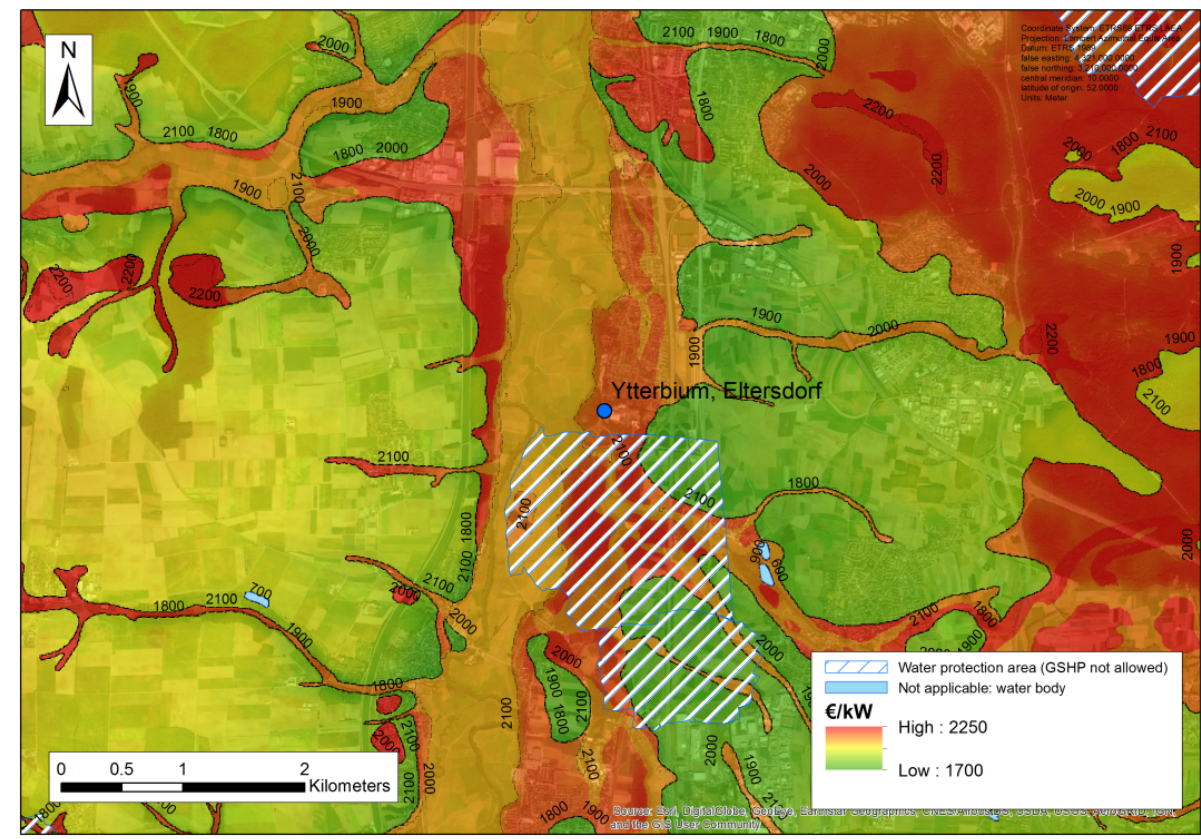

Figure 3. The EUR kW ${ }^{-1}$ map for double-U heat exchanger systems at Erlangen, Germany (from Perego et al., 2019b).

The implementation of the legislation is achieved through the local regulations that govern the installation of GSHEs. There are technical thresholds that dictate the licensing and registration procedures. The thresholds relate to depth of GSHE collector, changes in underground temperature, heat extraction rate and installed capacity. Below certain thresholds a simple notification process is possible. The average time to obtain a permit is between 30 to $90 \mathrm{~d}$. Permitting costs vary but are less than EUR 500 excluding professional fees. An Environmental Impact Assessment (EIA) is required for open loop GSHEs extracting groundwater, while closed loop collectors are mostly exempt from EIA. Approval of EIAs by regulatory authorities takes 3 to 6 months. Usually, monitoring is required for systems extracting groundwater. Where specific GSHE regulation is missing environmental, water and planning regulations apply. Environmental regulations protect groundwater aquifers under the Water Framework Directive and prohibit drilling shallow geothermal boreholes in certain circumstances. Where shallow borehole drilling is permitted casing and grouting is required.

\section{Discussion and conclusion}

The databases and maps presented in this paper compose and support the new, publicly available Decision Support System developed by the Cheap-GSHPs project (De Carli et al., 2019). All the tools can also be used directly by the experts, as standalone resources. Both the tools and databases have been built in order to support the design and the installation of new shallow geothermal systems; the particular innova- tion is that one software is able to elaborate and take into account all the aspects involved in the design of new shallow geothermal systems, including the geological, the technical, building demand and economical aspects. After inserting a series of simple inputs, the sizing of the borefield may be done with a simplified method based on the ASHRAE approach or with a detailed calculation based on the numerical tool CaRM (Capacity-Resistance method) (De Carli et al., 2010; Zarrella et al., 2011). Finally, the DSS generates different possible technical solutions and helps the user to identify the optimal solution based on his own preferences (initial costs, energy performance, life cycle assessment, etc.).

The goal of the DSS is to accelerate the decision-making process for designers and building owners as well as increasing market share of the technologies developed by the project. The proposed methodology for techno-economical maps has the same objective, of supporting the end-users as well as the administrator in the identification of the most suitable or unsuitable zones for new GSHP systems installation, or in the evaluation and comparison of the local technical and economic feasibility of different kinds of ground heat exchangers.

In addition to this techno-economical aspects, the system's final aim is to support decision-making, by providing stakeholders at all the level with a wide spectrum of necessary technical information and by proposing possible solutions.

Data availability. The data are available at https://cheap-gshp.eu/ (Cheap-GSHPs partners, last access: 26 August 2019.). 
Author contributions. AG, GDS, DB and JM worked to build up the Thermo-Geological Database and the Pan European geological map. MdC, GE and AZ developed the code and performed the simulations to build up the Pan-european Climatic Database and the Standard temporal profiles Database of building heating and cooling requirements. MdC, GE, AZ and AC worked also on the creation of the Decision Support System. FP and GE worked on the heat pumps database. RP, SP, AG and GDS worked on the techno-economical potential mapping. RP worked on the legislation framework. $A B$ is the EU project Cheap-GSHPs coordinator. GDS and RP prepared the manuscript with contributions from all co-authors.

Competing interests. The authors declare that they have no conflict of interest.

Special issue statement. This article is part of the special issue "European Geosciences Union General Assembly 2019, EGU Division Energy, Resources \& Environment (ERE)"'. It is a result of the EGU General Assembly 2019, Vienna, Austria, 7-12 April 2019.

Acknowledgements. The authors want to thank all the partners of the Cheap-GSHPs consortium.

Financial support. This research has been supported by the European Union's Horizon 2020 research and innovation program (grant nos. 657982, 792355).

Review statement. This paper was edited by Viktor Bruckman and reviewed by Mauro Cacace and one anonymous referee.

\section{References}

ASHRAE: ASHRAE Handbook: HVAC applications, Geothermal Energy, Atlanta, GA, US, chap. 34, 2011.

Badenes, B., Belliardi, M., Bernardi, A., De Carli, M., Di Tuccio, M., Emmi, G., Galgaro, A., Graci, S., Pockele, L., Vivarelli, A., Pera, S., Urchueguía, J. F., and Zarrella. A.: Definition of Standardized Energy Profiles for Heating and Cooling of Buildings, in Proceedings of the 12th REHVA Wolrd Congress, Aalborg, Denmark, 6, 611, 2016.

Bertermann, D., Klug, H., and Morper-Busch, L.: A pan-European planning basis for estimating the very shallow geothermal energy potentials, Renew. Energ., 75, 335-347, 2015.

Bertermann, D., Mueller, J., Galgaro, A., Dalla Santa, G., Cultrera, M., De Carli, M., Emmi, G., Zarrella, A., Psyk, M., Pockelé, L., Mezzasalma, G., Righini, D., Vercruysse, J., and Bernardi, A.: Innovative Helicoidal Ground Source Heat Exchanger Coupled with a New Timesaving Installation Technique, in: Proceedings of World Geothermal Congress 2020 (Reykjavik, Iceland, 26 April-2 May), 2020.

Carnieletto, L., Badenes, B., Belliardi, M., Bernardi, A., Graci, S., Emmi, G., Urchueguía, J. F., Zarrella, A., Di Bella, A., Dalla
Santa, G., Galgaro, A., Mezzasalma, G., and De Carli, M.: An European database for standardized energy profiles for heating and cooling of buildings with ground source heat pumps, Energies, 12, 2496, https://doi.org/10.3390/en12132496, 2019.

Cheap-GSHPS Project: Cheap and efficient application of reliable ground source heat exchangers and pumps, available at: https: //cheap-gshp.eu, last access: 26 August 2019.

Dalla Santa, G., Galgaro, A., Tateo, F., and Cola, S.: Modified compressibility of cohesive sediments induced by thermal anomalies due to a borehole heat exchanger, Eng. Geol., 202, 143-152, https://doi.org/10.1016/j.enggeo.2016.01.011, 2016a.

Dalla Santa, G., Galgaro, A., Tateo, F., and Cola S.: Induced thermal compaction in cohesive sediments around a borehole heat exchanger: laboratory tests on the effect of pore water salinity, Environ. Earth. Sci., 75:181, https://doi.org/10.1007/s12665015-4952-z, 2016b.

Dalla Santa, G., Peron, F., Galgaro, A., Cultrera, M., Bertermann, D., Mueller, J., and Bernardi, A.: Laboratory measurements of gravel thermal conductivity: an update methodological approach, Enrgy Proced., 125, 671-677, https://doi.org/10.1016/j.egypro.2017.08.287, 2017.

Dalla Santa, G., Cola, S., Secco, M., Tateo, F., Sassi, R., and Galgaro, A. Multiscale analysis of freeze-thaw effects induced by ground heat exchangers on permeability of silty-clays, Geotechnique, 69, 95-105, https://doi.org/10.1680/jgeot.16.p.313, 2019a.

Dalla Santa, G., Farina, Z., Anbergen, H., Rühaak, W., and Galgaro, A.: A comparative study on the relevance of computing freeze-thaw effects for borehole heat exchanger modelling, Geothermics, 79, 164-175, https://doi.org/10.1016/j.geothermics.2019.02.001, 2019b.

De Carli, M., Tonon, M., Zarrella, A., and Zecchin, R.: A computational capacity resistance model $(\mathrm{CaRM})$ for vertical groundcoupled heat exchangers, Renew. Energ., 35, 1537-1550, 2010.

De Carli, M., Bernardi, A., Cultrera, M., Dalla Santa, G., Di Bella, A., Emmi, G., Galgaro, A., Graci, S., Mendrinos, D., Mezzasalma, G., Pasquali, R., Pera, S., Perego, R., and Zarrella, A.: A database for climatic conditions around Europe for promoting GSHP solutions, Geosciences, 8, 71, https://doi.org/10.3390/geosciences8020071, 2018.

De Carli, M., Castelruiz Aguirre, A., Zarrella, A., Cardoso, L., Noye, S., Gast, R., Graci, S., Emmi, G., Bertermann, D., Mueller, J., Galgaro, A., Dalla Santa, G., Poletto, F., Mezzasalma, G., Contini, S., Urchueguía, J., Belliardi, M., Pasquali, R., and Bernardi, A.: Two software tools for facilitating the choice of ground source heat pumps by stakeholders and designers, in: Proceedings of the 13th REHVA World Congress, Bucharest, Romania, 26-29 May 2019, E3S Web of Conferences 111, 06023, TS15 https://doi.org/10.1051/e3sconf/201911106023, 2019.

Galgaro, A., Dalla Santa, G., Cultrera, M., Sassi, R., Scotton, P., Mueller, J., Bertermann, D., Mendrinos, D., Pasquali, R., Perego, R., Pera, S., Di Sipio, E., Cassiani, G., De Carli, M., and Bernardi, A.: An updated ground thermal properties database for GSHP applications, Geothermics, accepted, 2019.

Li, J. and Heap, A. D.: Spatial interpolation methods applied in the environmental sciences: A review, Environ. Model. Softw., 53, 173-189, 2014.

Mueller, J. Galgaro, A., Dalla Santa, G., Cultrera, M., Karytsas, C., Mendrinos, D., Pera, S., Perego, R., O’Neill, N., 
Pasquali, R., Vercruysse, J., Rossi, L., Bernardi, A., and Bertermann, D.: Generalized pan-european geological database for shallow geothermal installations, Geosciences, 8, 32, https://doi.org/10.3390/geosciences8010032, 2018.

Perego, R., Pera, S., and Galgaro, A.: Techno-Economic Mapping for the Improvement of Shallow Geothermal Management in Southern Switzerland, Energies, 12, 279, 2019a.

Perego, R., Pera, S., Galgaro, A., Dalla Santa, G., Cultrera, M., De Carli, M., Emmi, G., Bertermann, D., Mueller J., Mendrinos, D., Vercruysse, J., Pasquali, R., and Bernardi, A.: Economic, geological and technical potential mapping test for GSHP systems in Europe, in: Proceedings of the European Geothermal Congress, Den Haag, the Netherlands, 11-14 June 2019b.

Pockelé, L., Mezzasalma, G., Righini, D., Vercruysse, J., Cicolin, F., Cadelano, G., Galgaro, A., Dalla Santa, G., De Carli, M., Emmi, G., and Bernardi, A.: Innovative Coaxial Heat Exchangers for Shallow Geothermal, in: Proceedings of World Geothermal Congress 2020 (Reykjavik, Iceland, 26 April-2 May), 2020.
Stahl, K., Moore, R. D., Floyer, J. A., Asplin, M. G., and McKendry, I. G.: Comparison of approaches for spatial interpolation of daily air temperature in a large region with complex topography and highly variable station density, Agr. Forest Meteorol., 139, 224 236, 2006.

VDI-Gesellschaft Energietechnik (Ed.): 4640 Thermal Use of the Ground. Fundamentals, Approvals, Environmental Aspects, Part 1, Beuth Verlag GmbH, Berlin, Germany, 2010.

Zarrella, A., Scarpa, M., and De Carli, M.: Short time step analysis of vertical ground-coupled heat exchangers: the approach of CaRM, Renew. Energ., 36, 2357-2367, 2011. 